\title{
ARTIFICIAL HYBRIDIZATION BETWEEN DIFFERENT POLYPLOID LEVELS IN GLANDULARIA (VERBENACEAE) ${ }^{1}$
}

\author{
Otto T. Solbrig \\ Department of Botany, University of Michigan, Ann Arbor \\ and \\ Cornelius Passani and Roger Glass \\ Gray Herbarium, Harvard University, Cambridge, Massachusetts
}

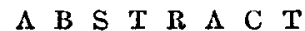

\begin{abstract}
The hexaploid North American species Glandularia elegans has been crossed with the South American diploid species G. stellaroides, G. peruviana, and G. pulchella. Analysis of the behavior of chromosomes at meiosis in the hybrid indicates that the chromosomes of $G$. pulchella are similar to one of the genomes of G. elegans. Non-homologous pairing and presence of multivalents also indicates that $G$. elegans is a segmental allohexaploid derived most likely from South American ancestors.
\end{abstract}

The genus Glandularia Gmelin is one of a large number of plant taxa with a North-South American disjunct distribution. In South America it grows in Argentina, Uruguay, southern Brazil, Paraguay, Bolivia, Chile, and Perú. In North America it is found in northern Guatemala, Mexico, and in the United States from South Carolina to Florida, west to California and north to Utah, and in Colorado, South Dakota, Illinois, and Ohio. Morphologically most species are similar, the major differences between taxa being leaf shape, and floral and fruit characteristics.

The North American species of the genus have been monographed by Perry (1933) who recognized 18 species. No complete monographic treatment exists for the South American species; Moldenke (1961-64), and Troncoso (1964, 1965) have clarified the classification of particular groups of species; Schnack and Covas (1944) have discussed the position of the genus and its validity. It is estimated that there are approximately 30-50 species in South America. Experimental work by Dermen (1936), Schnack and coworkers (Schnack and Covas, 1945a, b; Schnack and Gonzales, 1945; Schnack and Solbrig, 1953), Solbrig (1959, 1962, 1968, and unpubl.), Lewis and Oliver (1961), and others has shown that the South American species are largely diploid with $n=5$ (only 2 tetraploids have been found out of 20 species investigated), while the North American species are mostly hexaploid with $n=1$ i) (only 4 tetraploid species have been determined out of 15 species investigated). Furthermore, extensive hybridization programs undertaken by Schnack and coworkers and by Solbrig have shown that all South American species tested (10) are interfertile to some extent,

\footnotetext{
${ }^{1}$ Received for publication 31 May 1968.
}

the sterility of the hybrids varying between 5 and $90 \%$, approximately. Crosses made by Solbrig (unpubl.) have shown that all N.A. hexaploid species tested (5) are also interfertile and that in general hybrids are highly fertile $(80 \%$ or more pollen fertility).

The present work reports the results of artificial crosses between three South American diploid species and one North American hexaploid species. The object of the study was to gain some information regarding the degree of affinity between the species of the two continents and to investigate the genomic affinity of the species involved in the crosses.

Materad and methods-The diploid South American species, Glantularia pulchella Sweet, G. stellaroides Covas and Schnack, and two distinct morphological types of $G$. peruviana $\left(\mathrm{I}_{\text {.. }}\right)$ Small, were grown in greenhouses at Cambridge, Mass., and artificial crosses attempted with the North American hexaploid, G. elegans H.B.K. All flowers were emasculated and the styles pollinated repeatedly for about 7 days. Most attempted crosses were unsuccessful, but a few of the approximately 100 attempts produced fruits. These involved always $G$. elegans as the pistillate parent, and they yielded only a very few seeds. The seeds were stratified for about 3 months in moist sand and 15 plants obtained (Table 1). Meiotic preparations were made according to the squash technique, using aceto-carmine as a stain. All observations were made under a phase-contrast microscope. Pollen grains were stained with lactophenol cotton-blue, and 500 grains counted to obtain fertility estimates.

Mature hybrid plants were cloned and some of the cloned plants treated with colchicine in an aqueous solution at a concentration of $5 \times 10^{-2}$ 
TABLE 1. Characteristics of the species and hybrids ${ }^{\mathrm{a}}$

\begin{tabular}{|c|c|c|c|c|c|c|}
\hline \multirow[b]{2}{*}{ Character } & \multirow[b]{2}{*}{ peruviana } & \multicolumn{2}{|c|}{ elegans $\times$ peruviana } & \multirow[b]{2}{*}{ elegans } & \multirow{2}{*}{$\begin{array}{r}\text { elegans } \times \\
\text { pulchella }\end{array}$} & \multirow[b]{2}{*}{ pulchella } \\
\hline & & Tetraploid & Octoploid & & & \\
\hline Plant height & 12.5 & 10 & 15 & 22 & 12 & 7.5 \\
\hline Habit & $\begin{array}{l}\text { Decumbent- } \\
\text { semi-erect }\end{array}$ & Sprawling & Sprawling & Erect & Sprawling & Decumbent \\
\hline Internode length & 3.0 & 2.3 & 4.7 & 3.9 & 2.7 & 3.4 \\
\hline Leaf length & 3.2 & 2.7 & 4.5 & 4.2 & 3.5 & 1.7 \\
\hline Leaf width & 1.5 & 2.0 & 2.9 & 2.9 & 2.2 & 1.7 \\
\hline Leaf pubescence & $\begin{array}{l}\text { Short, } \\
\text { medium dense }\end{array}$ & $\begin{array}{l}\text { medium long, } \\
\text { medium dense }\end{array}$ & $\begin{array}{l}\text { medium long, } \\
\text { dense }\end{array}$ & $\begin{array}{l}\text { long, } \\
\text { medium dense }\end{array}$ & $\begin{array}{l}\text { long, } \\
\text { open }\end{array}$ & $\begin{array}{l}\text { long, } \\
\text { infrequent }\end{array}$ \\
\hline Leaf shape & Entire & Lobed & Lobed & Bipinnatifid & Bipinnatifid & Bipinnatifid \\
\hline Floral bract length & $5 \mathrm{~mm}$ & $4 \mathrm{~mm}$ & $5 \mathrm{~mm}$ & $5 \mathrm{~mm}$ & $4 \mathrm{~mm}$ & $4 \mathrm{~mm}$ \\
\hline Calyx length & $11 \mathrm{~mm}$ & $9 \mathrm{~mm}$ & $9.5 \mathrm{~mm}$ & $6 \mathrm{~mm}$ & $7 \mathrm{~mm}$ & $8 \mathrm{~mm}$ \\
\hline Corolla tube & $16 \mathrm{~mm}$ & $14 \mathrm{~mm}$ & $17 \mathrm{~mm}$ & $14 \mathrm{~mm}$ & $12 \mathrm{~mm}$ & $12 \mathrm{~mm}$ \\
\hline Corolla limb width & $12 \mathrm{~mm}$ & $12 \mathrm{~mm}$ & $14.5 \mathrm{~mm}$ & $10.5 \mathrm{~mm}$ & $10 \mathrm{~mm}$ & $10 \mathrm{~mm}$ \\
\hline Corolla color ${ }^{\mathrm{b}}$ & $\operatorname{Red}(19)$ & Red-purple(29) & Red-purple(29) & Purple(32) & Purple(33) & Purple(35) \\
\hline Style length & $14.5 \mathrm{~mm}$ & $13 \mathrm{~mm}$ & $16 \mathrm{~mm}$ & $11 \mathrm{~mm}$ & $7.5 \mathrm{~mm}$ & $8 \mathrm{~mm}$ \\
\hline Anther gland & absent & $0.1 \mathrm{~mm}$ & $0.25 \mathrm{~mm}$ & $0.3 \mathrm{~mm}$ & $0.5 \mathrm{~mm}$ & $0.9 \mathrm{~mm}$ \\
\hline Pollen stainability & $100 \%$ & $5 \%$ & $70 \%$ & $100 \%$ & $20 \%$ & $100 \%$ \\
\hline
\end{tabular}

a All measurements are in $\mathrm{cm}$ unless stated otherwise. Measurements here given represent averages of several plants.

b Color code number taken from the color dictionary of the Royal Horticultural Society of England.

M. The colchicine solution was applied in a cotton wad to the apical buds for a period of $72 \mathrm{hr}$, while the plants were in an atmosphere of high humidity and at elevated temperatures (ca. $30 \mathrm{C}$ ).

Results-Morphology of the hybrids-The $\mathrm{F}_{1}$ hybrids were intermediate between the parents in both foliar and floral characters including flower color. On the other hand they were less vigorous than the parents (particularly the $G$. elegans $\times G$. stellaroides cross), and the internodes were somewhat shorter (Table 1). The crosses of $G$. elegans with G. pulchella and G. peruviana bloomed normally and continuously through the year; the cross involving $G$. stellaroides on the other hand bloomed very seldom, producing only a few flowers rather than the usual showy racemose inflorescence characteristic of the genus.

Meiotic analysis-The parental species all showed normal pairing and chromosome segregation at meiosis. The plant of $G$. stellaroides used had 2 supernumerary chromosomes that did not align on the metaphase plate and did not divide but instead were usually incorporated in one of the microspores.

Glandularia elegans $\times G$. peruviana: tetraploid hybrid-Five plants were obtained in this cross. All showed similar meiotic behavior. The most conspicuous characteristic was the large number of multivalents, particularly quadrivalents. Several hundred cells were studied; of these 40 allowed an exact and unequivocal identification of all the associations. Of the 40 cells, only five had more than six pairs of chromosomes per cell, while six had no pairs at all. The other 29 cells had from one to six pairs (Table 2). Only one cell had no multivalents; most cells had two (18 cells) or more quadrivalent associations. Of all the chromosomes analyzed (800), $39.9 \%$ were associated in pairs, $59.6 \%$ were in multivalent associations, and $2.5 \%$ were not paired at all (Table 3).

Glandularia elegans $\times G$. peruviana: artificial octoploid-Two octoploid plants, the result of treating the corresponding hybrid with colchicine, were obtained. They showed mostly 20 pairs at meiotic metaphase and at diakinesis with regular separation to the poles in first anaphase, and normal development of the subsequent stages of meiosis, including tetrad formation and pollen development. However, occasional univalents and multivalents (mostly trivalents and quadrivalents) were observed. Seventy-two percent of the pollen stained with lacto-phenol cotton-blue and was normal looking morphologically, although $24 \%$ of the pollen grains were tetracolpate instead of tricolpate, as is universally found in the parental species.

Glandularia elegans $\times G$. pulchella: tetraploid hybrid-Nine plants were obtained, all having similar meiotic behavior. In this cross 42 cells could be analyzed exactly. A significantly larger number of bivalents could be observed than in the $G$. elegens $\times G$. peruviana cross. Seventeen of the 42 cells showed more than six pairs; no cell had less than three bivalents. Most cells had at least one quadrivalent association, although none had more than three, and a large number (10) had no multivalent associations at all. More 
TAHLE 2. Number of cells with pairs and tetravalent associations

\begin{tabular}{ccc}
\hline Cells with: & $\begin{array}{c}\text { elegans } \times \\
\text { peruviana } \\
(4 \times)\end{array}$ & $\begin{array}{c}\text { elegans } \times \\
\text { pulchella } \\
(4 \times)\end{array}$ \\
\hline I II & 6 & 0 \\
I II & 2 & 0 \\
3 II & 6 & 0 \\
4 II & 6 & 4 \\
5 II & 9 & 5 \\
6 II & 6 & 9 \\
7 II & 10 & 7 \\
8 II & 1 & 3 \\
9 II & 3 & 11 \\
10 II & 1 & 0 \\
& 0 & 3 \\
No multivalents & 1 & 10 \\
IV & 13 & 22 \\
2 IV & 18 & 8 \\
3 IV & 5 & 0 \\
4 IV & 1 & 0 \\
5 IV & 2 & 42 \\
Total cells & 40 & \\
\hline & & \\
\hline
\end{tabular}

TABLE 3. Frequency of different metaphase associations in the hybrids

\begin{tabular}{lcc}
\hline & $\begin{array}{c}\text { elegans } \times \\
\text { peruviana } \\
(4 \times)\end{array}$ & $\begin{array}{c}\text { elegans } \times \\
\text { pulchella } \\
(4 \times)\end{array}$ \\
\hline Univalents & $2.5 \%$ & $3.0 \%$ \\
Pairs & $37.9 \%$ & $60.7 \%$ \\
Total multivalents & $59.6 \%$ & $36.3 \%$ \\
Trivalents & $12.0 \%$ & $9.7 \%$ \\
Tetravalents & $33.9 \%$ & $22.5 \%$ \\
Other & $14.7 \%$ & $4.1 \%$ \\
\hline
\end{tabular}

significantly, 3 cells showed 10 pairs (perfect pairing) and 11 cells had 8 pairs. Of all the chromosomes analyzed $60.7 \%$ were associated in pairs, $36.3 \%$ were in multivalents, and $3 \%$ were not paired at all (Table 3).

Glandularia elegans $\times$ G. stellaroides: tetraploid hybrid - This cross was completely sterile; only one plant produced flowers, and meiosis was arrested in the microsporocytes so that no meiotic analysis could be undertaken.

Discussion-Because of the high degree of sterility of the $G$. elegans $\times G$. stellaroides cross, the discussion will be confined to the other two crosses.

According to the generally accepted theory, pairing of chromosomes or chromosome segments at meiosis indicates homology (defined usually as a similar arrangement of alleles) between the pairing segments, and lack of pairing indicates non-homology . Consequently, in a cross between a hexaploid species with 15 chromosomes and a diploid species with 5 chromosomes, the predicted associations are a maximum of 5 pairs and 10 univalents, to a minimum association of 20 univalents. Any pairing in the hybrid is interpreted as indicating homology between the chromosome segments of the parental species. If multivalent pairing is found in the hybrid, it is assumed that chromosomal rearrangements, specifically translocations, have taken place in one or both of the species, so that the homologous segments are now located in more than one chromosome.

Nevertheless, the general hypothesis cannot explain the presence of more than five bivalents in the hybrid, nor the existence of multivalent associations involving more than five chromosomes. These chromosomal associations (encountered in both hybrids) indicate that some pairing is taking place between the chromosomes derived from $G$. elegans. Since pairing in $G$. elegans is normal, by definition the hybrid shows nonhomologous pairing.

The pairing relationships of the hybrid between diploid $G$. peruviana and diploid $G$. pulchella are of interest in this connection. The artificial hybrid between these two species is highly sterile (pollen fertility less than $30 \%$; seed set less than $1 \%$ ). Nevertheless bivalent formation at meiosis is practically perfect (Schnack and Solbrig, 1953). Fertility can be restored to a large extent, however, when the number of chromosomes of the hybrid is doubled through the use of colchicine (fertility of the tetraploid hybrid, approximately $70 \%$ ). Since the G. peruviana $\times$ G. pulchella diploid hybrid forms five bivalents, the tetraploid hybrid that is produced by colchicine is expected to form up to five quadrivalents since all the chromosomes have been now doubled. However, pairing of chromosomes at meiosis in the tetraploid hybrid is largely "diploid" pairing (most common associations 10 II or 8 II +1 IV). The meiotic behavior in these hybrids can obviously not be explained satisfactorily solely on the basis of homologous pairing.

The behavior of the G. peruviana $\times$ G. pulchella diploid and tetraploid hybrids is an experimental verification of segmental allopolyploidy as predicted by Stebbins (1947). In a segmental allopolyploid the chromosomes of the parental species have segments that are homologous and others that are not. The diploid hybrid between such species shows a high degree of bivalent formation at meiosis. This involves pairing between the homologous segments of the otherwise nonhomologous chromosomes. Nevertheless, random segregation of chromosomes and crossing-over produce gametes with chromosomes of mixed origin. Such gametes are usually deficient for certain chromosome segments and duplicated for others and consequently are sterile.

In the tetraploid segmental allopolyploid hybrid pairing takes place preferentially between 
Fig. 1. Artificial hybrids and polyploids produced between Glandularia pulchella, G. peruviana, and G. elegans; their chromosome number and pairing relationships.

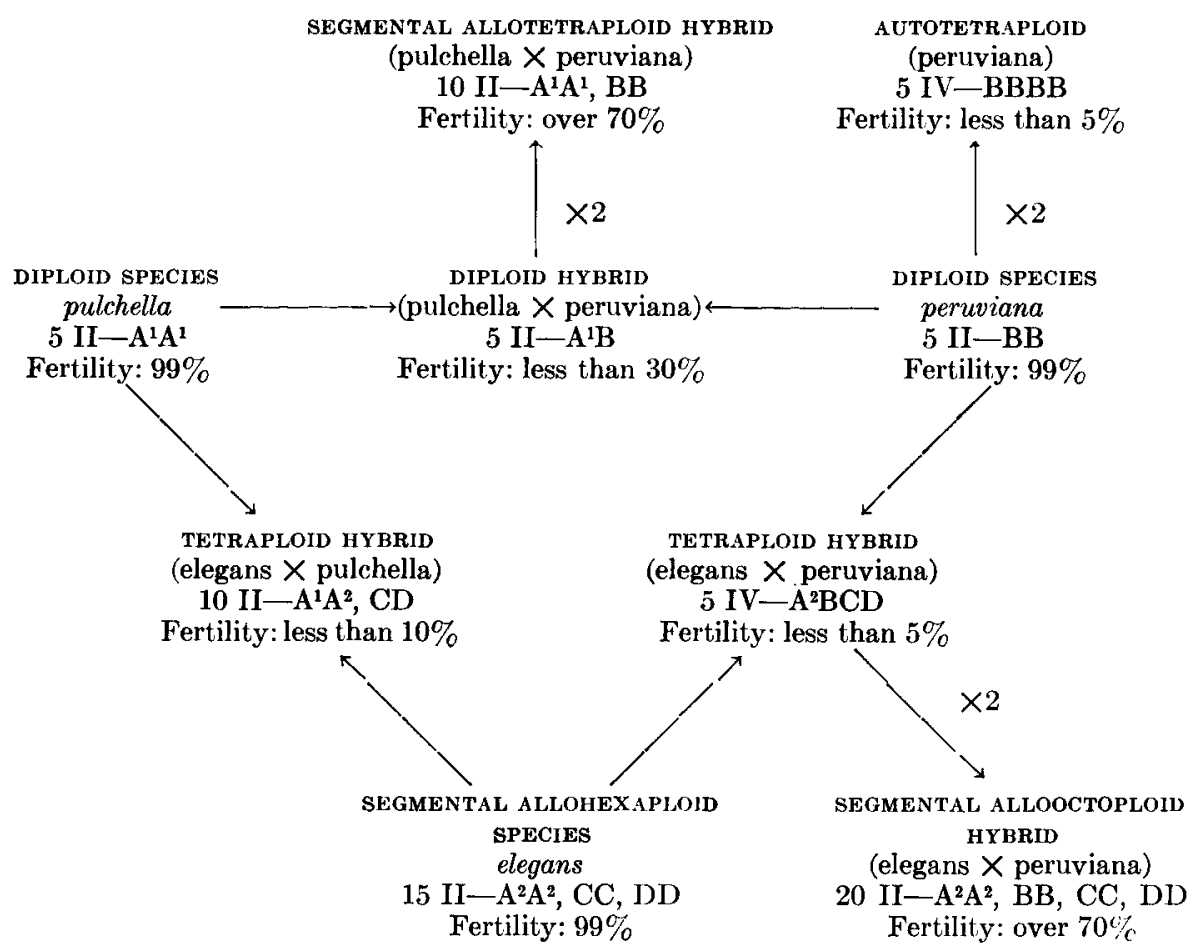

sister chromosomes (that are, of course, completely homologous). Bivalents are formed again at meiosis, but segregation and crossing-over do not produce deficient gametes, and fertility is restored. That preferential pairing can occur and that it may be genetically determined has now been demonstrated for the allohexaploid wheats (Riley and Chapman, 1958).

The behavior of the $G$. elegans $\times G$. pulchella and $G$. elegans $\times G$. peruviana hybrids can be explained also on the basis of the segmental allopolyploid hypothesis of Stebbins. Assuming that $G$. elegans is a segmental allohexaploid species, its three five-chromosome genomes have some common segments. Nevertheless pairing is normal on account of the preferential pairing of sister chromosomes characteristic of segmental allopolyploids. If such a plant is crossed with still a fourth diploid species, all four genomes will have certain homologous segments, but no chromosome will have any identical partner. Such a situation should produce a large number of multivalent associations with a maximum association of 5 IV. Such is the behavior of the $G$. elegans $\times G$. peruviana cross.

On the other hand if a segmental allohexaploid (as G. elegans is assumed to be) is backcrossed to one of its three parental species, two of the four genomes now present in the hybrid will be completely homologous or largely so and two will not. Such a situation should lead (when preferential pairing takes place) to the formation of pairs between the truly homologous genomes and by necessity as well between the remaining nonhomologous ones. This is, of course, the situation observed in the $G$. elegans $\times G$. pulchella cross (Fig. 1).

If this hypothesis is correct then doubling of the chromosomes in the hybrid should restore fertility. Such an artificial allooctoploid has been obtained by treating the $G$. elegans $\times G$. peruviana hybrid with colchicine. The resultant plant had 20 pairs of chromosomes as predicted, and fertility had been largely restored (Fig. 1). This is held as direct experimental confirmation of the hypothesis here proposed to explain the chromosomal behavior in the hybrids.

The morphological evidence tends to confirm the hypothesis that is being advanced. Glandularia elegans resembles $G$. pulchella in leaf shape, flower color, and flower shape more than it does $G$. peruviana (Table 1). Nevertheless, it is impossible to state that $G$. pulchella is ancestral to $G$. elegans, and probably it is not a direct ancestor. Glandularia pulchella is closely allied morphologically and genetically to a group of South American species, such as $G$. parodii, $G$. santiaguensis, and $G$. dissecta. Crosses between G. pulchella and these other species produced hybrids that are fertile (pollen fertility always more than $50 \%$ ) and a very high degree of pairing (Schnack and Covas, 1945a; Solbrig, 1968, and unpubl.). Some chromosomal rearrangements in the genomes of these species as compared to those of $G$. pulchella 
have, however, been observed. Any of these species, or a form ancestral to all of them, could have been involved in the evolution of $G$. elegans. On the basis of the present study it appears almost certain that the ancestral species must have been of South American origin. Further support is given by the fact that diploid species are only found in South America and that the variability of the genus is greatest in South America.

On the basis of the pairing relations observed in the crosses here reported, the following genomic formulas are proposed: $G$. pulchella, $\mathrm{A}^{1} \mathrm{~A}^{1}: G$. peruviana, $\mathrm{BB}$; and $G$. elegans, $\mathrm{A}^{2} \mathrm{~A}^{2}, \mathrm{CC}, \mathrm{DD}$. It should be stated, however, that all four genomes are related and appear to have considerable segments in common.

An interesting unanswered question is: What determines preferential pairing of the truly homologous chromosomes in the presence of partially homologous ones? As already stated there is evidence that indicates that such meiotic behavior, at least in certain cases, is under direct genetic control. Unfortunately nothing is known about the nature of the pairing mechanisms. The evidence from Glandularia would suggest that perhaps there is a "dosage" effect proportional to the degree of homology between chromosomes. This requires, however, a chromosomally determined pairing mechanism, and the evidence so far seems to rule out such a mechanism.

\section{LITERATURE CITED}

Dermen, $\mathrm{H}$. 1936. Cytological study and hybridization in two sections of Verbena. Cytologia 5: 160-170.

Lewis, W. H., and R. L. Oliver. 1961. Cytogeography and phylogeny of the North American species of Verbena. Amer. J. Bot. 48: 638-642.

Moldenke, H. N. 1961-1964. Materials towards a monograph of the genus Verbena. Phytologia 8: 95 , and following.

Perny, L. M. 1933. A revision of the North American species of Verbena. Ann. Mo. Bot. Gard. 20: 239-356.

Riley, R., and V. Chapman. 1958. Genetic control of the cytologically diploid behavior of hexaploid wheat. Nature (London) 182: 713-715.

Schnack, B., AND G. Covas. 1944. Nota sobre la validez del género Glandularia (Verbenaceae). Darwiniana 6: 469-476.

1045a. Hibridacion interespecifica en Glandularia (Verbenaceae). Darwiniana 7: 71-79.

, AND —. 1945b. Un hibrido interespecifico del género Glandularia ( $G$. peruviana $\times G$. megapolamica). Rev Argent. Agron. 12: 224-229.

_- - AND F. F. GonzaLes. 1945. Estudio morfológico y citogenético del hibrido Glandularia santiaguensis $\times$ G. megapotamica. Rev. Argent. Agron. 12: 285-290. , ANd O. T. Solbrig. 1953. El hibrido Glandularia laciniata $\times G$. peruviana y su anfidiploide artificial. Rev. Fac. Agron. Univ. Nac. La Plata 29: $255-266$.

Solbrig, O. T. 1959. In Documented chromosome numbers in plants. Madroño 15: 50-51. - 1962. In Documented chromosome numbers in plants. Madroño 16: 267.

1968. Fertility, sterility, and the species problem. In V. Heywood [ed.], Modern methods in plant taxonomy. Academic Press, London. (In press.)

Stebrins, G. L. 1947. Types of polyploids: their classification and significance. Advan. Genet. 1: 403-429.

Troncoso, N. S. 1964. Dilucidación de las especies platenses de Glandularia (Verbenaceae) de hojas disectas. Darwiniana 13: 468-485.

1965. Glandularia, p. 132-140. In A. L. Cabrera [ed.], Flora de la Provincia de Buenos Aires. Vol. 5. I.N.T.A., Buenos Aires, Argentina. 